\title{
Health Disparities Research with American Indian Communities: The Importance of Trust and Transparency
}

\section{Authors: Monica C. Skewes, Vivian M. Gonzalez, Julie A. Gameon, Paula FireMoon, Emily Salois, Stacy M. Rasmus, Jordan P. Lewis, Scott A. Gardner, Adriann Ricker, and Martel Reum}

This is the peer reviewed version of the following article: [Health Disparities Research with American Indian Communities: The Importance of Trust and Transparency. American Journal of Community Psychology (2020)], which has been published in final form at https://doi.org/10.1002/ ajcp.12445. This article may be used for non-commercial purposes in accordance with Wiley Terms and Conditions for Use of Self-Archived Versions: https://authorservices. wiley.com/authorresources/Journal-Authors/licensing/self-archiving.html\#3.

Skewes, Monica C., Vivian M. Gonzalez, Julie A. Gameon, Paula FireMoon, Emily Salois, Stacy M. Rasmus, Jordan P. Lewis, Scott A. Gardner, Adriann Ricker, and Martel Reum. "Health Disparities Research with American Indian Communities: The Importance of Trust and Transparency." American Journal of Community Psychology 66, no. 3-4 (July 11, 2020): 302313. doi:10.1002/ajcp.12445.

Made available through Montana State University's ScholarWorks

scholarworks. montana.edu 
Health Disparities Research with American Indian Communities: The Importance of Trust and Transparency

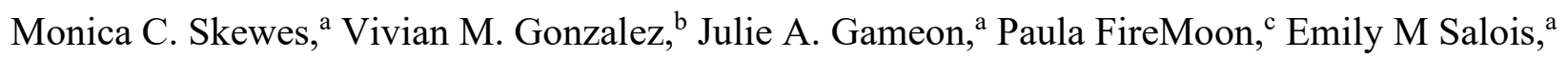
Stacy M. Rasmus, ${ }^{\mathrm{d}}$ Jordan P. Lewis, ${ }^{\mathrm{e}}$ Scott A. Gardner, ${ }^{\mathrm{a}}$ Adriann Ricker, ${ }^{\mathrm{c}} \&$ Martel Reum ${ }^{\mathrm{c}}$

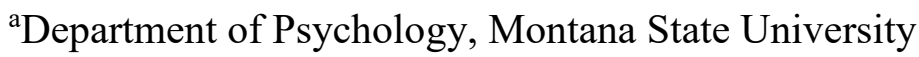

${ }^{b}$ Department of Psychology, University of Alaska Anchorage

${ }^{\mathrm{c}}$ Fort Peck Community College

${ }^{\mathrm{d}}$ Center for Alaska Native Health Research, University of Alaska Fairbanks

e Department of Family Medicine and Biobehavioral Health, University of Minnesota Medical School, Duluth Campus

Corresponding Author. Correspondence concerning this document should be addressed to Monica C. Skewes, Department of Psychology, Montana State University, 319 Traphagen Hall, Bozeman, MT 59715, monica.skewes@montana.edu.

Author Note. This research was funded by a grant from the National Institute of General Medical Sciences of the National Institutes of Health under Award Number 5P20GM104417-02. The content is solely the responsibility of the authors and does not necessarily represent the official views of the National Institutes of Health. The authors express our sincere, heartfelt gratitude to the Substance Abuse and Resilience Project Community Advisory Board and to the participants who generously shared their knowledge and experiences with us. We also wish to thank Arthur W. Blume, Dennis Donovan, and Joseph P. Gone for their generous guidance on the development of the research project described in this manuscript. 


\begin{abstract}
American Indian and Alaska Native (AI/AN) communities experience notable health disparities associated with substance use, including disproportionate rates of accidents/injuries, diabetes, liver disease, suicide, and substance use disorders. Effective treatments for substance use are needed to improve health equity for AI/AN communities. However, an unfortunate history of unethical and stigmatizing research has engendered distrust and reluctance to participate in research among many Native communities. In recent years, researchers have made progress toward engaging in ethical health disparities research by using a community based participatory research (CBPR) framework to work in close partnership with community members throughout the research process. In this methodological process paper, we discuss the collaborative development of a quantitative survey aimed at understanding risk and protective factors for substance use among a sample of tribal members residing on a rural AI reservation with numerous systems-level barriers to recovery and limited access to treatment. By using a CBPR approach and prioritizing trust and transparency with community partners and participants, we were able to successfully recruit our target sample and collect quality data from nearly 200 tribal members who self-identified as having a substance use problem. Strategies for enhancing buy-in and recruiting a community sample are discussed.
\end{abstract}

Key words: American Indian/Alaska Native, substance use, CBPR, methods, process

Conflict of Interest Statement: None of the authors have any potential conflicts of interest related to this manuscript. 


\section{Introduction}

Despite high rates of abstinence from alcohol and other drugs (Cunningham et al., 2016), American Indian and Alaska Native (AI/AN) people suffer from significant health disparities associated with substance misuse (Grant et al., 2015, 2016; Riekmann et al., 2012; Spicer et al., 2003). Based on national epidemiological research, there are higher rates of alcohol and drug use disorders among AI/ANs compared with other racial or ethnic groups (Grant et al., 2015, 2016), although these differences in prevalence are reduced when other sociodemographics associated with these disorders are controlled for (e.g., education and income level). Substance use disorder (SUD) also is associated with other health disparities affecting Native communities. For example, AI/ANs reporting heavy alcohol use are at increased risk of developing type 2 diabetes (Tann et al., 2007), hypertension (Saremi et al., 2004), liver disease (Centers for Disease Control and Prevention, 2018), and having a child diagnosed with fetal alcohol spectrum disorder (May et al., 2002). Compared to other ethnic groups, AI/AN people also have disproportionally high mortality rates associated with alcohol and other drug use through accidents, injuries, and suicide (Indian Health Service [IHS], 2018; Riekmann et al., 2012; Wexler et al., 2008).

Health disparities experienced by AI/AN people can be attributed to inequities in environmental and social determinants of health, including unhealthy physical environments, poverty, discrimination, and traumatic stress (Pruss-Ustun et al., 2017; Whitesell et al., 2012). For example, experiences of current discrimination and historical trauma have been shown to negatively impact mental health and health behaviors as well as substance use problems among AI/AN populations (Wiechelt et al., 2011; Whitbeck et al., 2003; Whitesell et al., 2012). Further, $\mathrm{AI} / \mathrm{ANs}$ are at increased risk for trauma exposure both in early childhood and adulthood, which is associated with greater rates of posttraumatic stress disorder (PTSD). In turn, PTSD symptoms 
are strongly associated with substance use and SUDs among AI/AN populations (Manson et al., 2005; Whitesell et al., 2009). Effective SUD prevention and treatment interventions are needed for reducing health disparities and improving health equity in Indian Country.

\section{Barriers to Substance Use Disorder Treatment}

While AI/AN communities are disproportionally affected by substance use problems, many reservation communities are underserved with regard to health services to address these issues and are located in rural, geographically isolated areas with limited access to treatment (Zuckerman et al., 2004). Community health clinics serving AI/ANs often are understaffed or otherwise underresourced and unable to meet the treatment needs of the community (Zuckerman et al., 2004). If a community lacks local treatment services, people must travel to seek care, which adds an additional barrier and may prevent them from receiving needed services (Duran et al., 2005; Manson, 2000). Aside from issues related to access, there may be tensions between AI/AN communities and Western medical practitioners on the integration of traditional healing elements (e.g., sweat lodge, prayer ceremonies, drumming) in substance use treatment programs (Novins et al., 2004). This tension between traditional healing and Western practices may serve as an added barrier to treatment, preventing $\mathrm{AI} / \mathrm{ANs}$ from using services that may not meet their cultural needs or align with their worldviews (Novins et al., 2004). Thus, barriers include both access to care and limited options for locally desirable, culturally grounded SUD treatments.

Effective treatments for SUD are essential to reduce health disparities and improve health equity for Native communities; however, AI/AN people have been vastly underrepresented in SUD treatment research. A review of SUD treatment studies published between 1968 and 2011 found 24 studies reporting outcome data for AI/ANs, with only eight of these incorporating traditional cultural elements into treatment (Greenfield \& Venner, 2012). While more recent 
studies have attempted to utilize evidence-based treatments (EBTs) to address SUD among AI/ANs (e.g., Campbell et al., 2015; Venner et al., 2016) there are still only a small number of SUD treatment programs implemented and evaluated with $\mathrm{AI} / \mathrm{AN}$ clients.

\section{Barriers to Substance Use Disorder Research}

Although there are Native communities calling for research focused on SUD and associated health disparities, progress has been limited by several barriers to studying this sensitive topic. In particular, recruitment of AI/ANs into SUD research studies has been limited by stigma associated with addictive behaviors, stereotypes about AI/ANs and alcohol, and distrust of research among AI/ANs resulting from a history of research ethics violations in Native communities (Mail, 2002; Mohatt et al., 2004; Yuan et al., 2010). There is a disturbing history of colonizing research studies conducted on (not with) Native communities in the U.S., particularly with regard to substance use. For example, the Barrow Alcohol Study focused on alcohol problems among the Inupiaq people of Utqiagvik (formerly Barrow), Alaska, and was conceived and conducted by non-Natives in 1979 (Foulks, 1989). The study was conducted and dissimenated with minimal community involvement and oversight (Beauvais, 1989), and without consideration of the cultural and contextual appropriateness of the study measures and procedures. Findings regarding the prevalence of alcohol problems in the sample were overgeneralized to the wider population of Alaska Natives without consideration of the historical and sociocultural context that contributed to alcohol problems, or how the methods used may have influenced the findings (Foulks, 1989). Further, there was a devastating premature disclosure of the findings that led to a New York Times headline declaring this AN community to be a "society of alcoholics," further stigmatizing AN people and leading to increased distrust of research and researchers (Foulks, 1989). Since the Barrow Alcohol Study, research examining 
substance use among AI/ANs has been relatively limited in comparison to research focused on other populations, despite large (and growing) health disparities attributed to SUD. More recently, successful studies have focused on understanding strengths and protective factors, used qualitative methods, and engaged AI/AN communities in equitable research partnerships (e.g., Allen et al., 2019; Mohatt et al., 2004; 2007; Rasmus et al., 2019; Wexler et al., 2015).

\section{Community-Based Participatory Research}

Community-based participatory research (CBPR) is considered a best practice for health disparities research with $\mathrm{AI} / \mathrm{AN}$ communities, and many tribes prefer or even require $\mathrm{CBPR}$ for studies conducted with their people (Burhansstipanov et al., 2005; Dillard et al., 2018). The CBPR framework is a partnership approach to research that emphasizes equitable relationships between academic researchers and community co-researchers and involves community participation at every step in the research process, from study design and implementation to interpretation and dissemination of findings (e.g., Wallerstein \& Duran, 2006). Researchers engaged in CBPR aim to develop trusting, long-term relationships with community members, study topics that matter to the community, and acknowledge that sustainable solutions to problems reside within the community. The goal of CBPR is to identify and build upon existing strengths, empowering the community to effect change (Wallerstein \& Duran, 2010). As many Native communities have declared, "No research about us, without us."

In this methodological process paper, we discuss the development of a quantitative study study aimed at understanding risk and protective factors for substance use among a sample of tribal members residing on a rural AI reservation with numerous systems-level barriers to recovery and limited access to treatment. First we describe how the use of CBPR to establish a long-term equitable relationship between academic and community co-researchers facilitated our 
ability to gather extensive quantitative data on sensitive topics (e.g., substance use, mental health, early childhood trauma) from nearly 200 AI reservation residents who self-identified as having a substance use problem after only a single recruitment effort. While the main survey results are beyond the scope of this paper, here we describe the methods for developing our Substance Use and Recovery Survey and report results relevant to participants' reactions to participating in the study. Second, we describe future directions for using the data we gathered to address SUD and promote health equity in AI reservation communities.

\section{The Substance Abuse and Resilience Project_Overview and Formative Work}

The Substance Abuse and Resilience Project represents a six-year collaboration between academic and community research partners from a remote reservation in the Northern Plains region of the U.S. The goals of the project include the following: 1) to build trusting and respectful relationships between the university and the community partners, 2) to understand AI community perspectives of substance use and recovery on the reservation, and 3) to develop a culturally grounded intervention to promote healing from SUD. Using a CBPR framework, we aimed to accomplish these goals through sequential phases of the project. The research methods were informed by the processes successfully used in the pioneering People Awakening Project in Alaska (e.g., Allen et al., 2014; Mohatt, Hazel et al., 2004; Rasmus et al., 2019).

In Phase I, we established the goals of the project and focused on relationship building. The academic partners visited the reservation regularly (about once per month) for one year before any data collection took place. We began with informal meetings with community members interested in and knowledgeable about substance abuse and other mental health concerns affecting the reservation. These community members included tribal leaders, Elders, mental health and SUD treatment providers, individuals in long-term and short-term recovery 
from SUD, affected family members, and community members still struggling with addiction. Through these informal conversations, the academic partners gained insight into the needs and priorities of the community, and the community members gained insight into the motives and interests of the researchers. The academic partners also made several visits with no agenda other than to visit and learn about the community by attending local events and celebrations. Through these visits, the academic researchers began to understand the complexity of SUD recovery on the reservation, gained insight into the barriers to recovery, and engaged in the critical selfreflection necessary for developing cultural humility and knowledge co-production. Before moving forward with the research, a financial agreement and subaward with the local tribal college was established to ensure that grant funding was funneled directly into the community, rather than being managed solely by the academic partners. A subaward also helped support local capacity-building, community engagement and investment in the project, and demonstrated respect for tribal sovereignty. We then hired a local project manager, a well-respected tribal member with extensive community ties, a master's degree in education, and years of experience with CBPR and health disparities research. The project manager took the lead in assembling a Community Advisory Board (CAB) to guide the next phases of the project. The relationships we established at the onset of the project have persisted throughout the subsequent phases.

Following this formative work, our new partnership collaborated on the development of Phase II of the project, which aimed to understand local perspectives on substance use and recovery on the reservation. The $\mathrm{CAB}$ and project manager suggested that a qualitative study was the best place to start, and that conducting interviews with key informants would help us identify important variables and develop hypotheses to test using quantitative methods in a future study. Qualitative methods were more accessible and familiar to the community partners, and 
also aligned with AI storytelling traditions. Furthermore, we believed that conducting key informant interviews would help build trusting relationships with community members who did not yet know our team, and strengthen our relationships with those who did. Therefore, we collaborated over several months to carefully develop a semi-structured interview guide that we believed would yield important data to guide and inform future research aimed at understanding the risk and protective factors influencing SUD and recovery among reservation residents.

For this Phase II key informant interview study, the community partners nominated individuals who they felt should participate in semi-structured, in-depth interviews about reservation life, health and illness, and addiction and recovery. Interviews took place with a diverse group of 25 key informants, including males and females from different age groups, cultural backgrounds, and spiritual traditions. Each participant was interviewed on two separate occasions, with each segment of the interview lasting 1-2 hours. Findings showed that individual, family, and community health were all seen as vitally important and interconnected (Skewes et al., 2019). Racism and discrimination were noted as particularly formidable barriers to recovery, as well as causes of substance use problems (Skewes \& Blume, 2019). Moreover, substance abuse was seen as a symptom of traumatic events such as child abuse, violence, and historical trauma, and as a problem requiring a community orientation to healing (Skewes et al., 2019). Ultimately, cultural connection was seen as key to recovery, and participants emphasized the powerful recovery potential inherent in reconnecting tribal members with their traditional Native language, ceremonies, and ways of life (Skewes et al., 2019).

After thematic coding of the interview data and interpretation with the CAB, we presented findings to the broader community via an interactive community gathering and took notes on additional feedback that emerged from the discussions. Community members 
emphasized the key roles of trauma, poverty, racism, and lateral violence in the development of addiction problems, and noted the difficulty of maintaining sobriety while living on the reservation and engaging with relatives who were still drinking or using. They called for cultural approaches to treatment (e.g., sweat lodge ceremony, a return to traditional ways) in addition to greater access to typical Western treatments. Although they felt that formal treatment was useful, community members expressed frustration with the many logistical barriers to treatment, and noted that even the most successful treatment programs are doomed to fail unless adequate aftercare support services can be provided. The community feedback largely supported the themes that emerged from the interview data, and also highlighted the dire need for additional addiction treatment services on the reservation.

Our partnership then embarked upon Phase III of the project, the Substance Use and Recovery Survey. The rationale for the study was to empirically test associations between the risk and protective factors identified by community members in Phase II of the project for the purpose of identifying targets for intervention, and to examine the psychometric properties of the assessment instruments for use in future intervention studies. To identify constructs to assess in the survey and the population of focus, our partnership discussed the qualitative findings and community feedback in relation to the extant literature on SUD treatment and recovery. We collectively selected constructs to assess in a survey of tribal members who self-identified as struggling with their substance use and wanting or trying to recover. We aimed to assess culturally and locally relevant risk and protective factors suggested by the interview data-for example, lack of social support/lateral violence, racial trauma, and lack of positive cultural identity were identified as culturally specific risk factors, whereas spirituality, communal mastery, and enculturation were identified as protective factors (Skewes et al., 2019). 
After agreeing upon the constructs to include, we then began to develop the survey instrument. The academic partners presented existing assessment instruments to the community partners for consideration and we discussed specific measures to use, items to rephrase or modify, ordering of measures, and demographic and background information to include. Constructs included those suggested by the academic partners as well as those suggested by the community partners based on their hypotheses regarding factors that may be protective in their community. For example, community partners suggested inquiring whether participants had been given an Indian name, which they believe is an important protective factor. The academic partners, in turn, proposed that some commonly used measures be included, such as assessments of self-efficacy and craving, due to their predictive validity in substance abuse research with other populations (e.g., Adamson et al., 2009; Hartz et al., 2001). We made efforts to include instruments that had been used in previous research with $\mathrm{AI} / \mathrm{AN}$ participants, and made minor modifications to improve readability and clarity and to reflect local terminology. In forming the survey instrument, the community partners proposed asking questions about hypothesized protective factors (e.g., ethnic identity and spirituality) before posing questions about risk factors (e.g., childhood adversity and post-traumatic stress symptoms) as a way to emphasize cultural and community strengths. Through these discussions, we achieved consensus on the final survey instrument, which was deemed appropriate, acceptable, and understandable by our partnership.

The resulting survey instrument included a battery of measures, including wellestablished measures commonly used in SUD research (e.g., Timeline Followback to assess alcohol and drug consumption; Sobell \& Sobell, 1992) and instruments used in other health disparities research with AI/AN communities (e.g., Historical Loss Scale; Whitbeck et al., 2004). We also developed several questions specific to AI people (e.g., "Did you ever attend boarding 
school?") and to this specific reservation (e.g., "Have you received treatment at [the onreservation treatment center]?"). We aimed to ask questions about risk and protective factors supported by the extant literature on SUD among AI/ANs as well as those that emerged from our qualitative interviews. We also collected data on substance use behaviors, consequences, and other associated factors (e.g., quality of life). Finally, we administered three items from the Reactions to Research Participation Questionnaire (RRPQ; Newman et al., 1999) that have been shown to effectively assess participants' experiences with taking part in research (Hohnson \& Benight, 2003). After the CAB approved the survey instrument and study methods, we secured approval from the reservation's tribal IRB and the university's IRB and began recruitment. Next we describe our recruitment strategy and process of conducting the Substance Use and Recovery Survey, present descriptive data from our sample, report participant reactions to the survey, and offer reflections on the lessons we learned along the way.

\section{Participant Recruitment and Process}

Inclusion criteria included being a tribal member residing on the reservation, aged 18 or older, who self-identified as "having a substance use problem and wanting or trying to change your alcohol or drug use.” These criteria were discussed and agreed upon by the academic and community co-researchers as a way to cast a broad net, with the goal of assessing key variables among tribal members who may be candidates for a future intervention study. Recruitment began with the local project manager making a visit to the reservation-based outpatient SUD treatment center and making an announcement to one of the therapy groups $(N=8)$. She explained the history of the project and the purpose of the survey, including the types of questions that would be asked and the compensation that would be offered ( $\$ 50$ for approximately two hours of data collection, as is customary for research on this reservation). She also emphasized that the 
information they provided in the survey would be kept confidential, within the limits allowed by law. The project manager invited the group members to come to the tribal college library the following week for one-on-one data collection sessions if they wanted to participate. After this initial announcement, all subsequent recruitment took place via word of mouth.

After a brief conversation to verify eligibility criteria, paper-and-pencil surveys were administered individually to participants, with two academic research partners and three community research partners serving as interviewers. All interviewers were trained to administer the survey instruments by the project's principal investigator and a practice run of the data collection procedures was completed with two volunteers from the community (data from these two surveys were not included in analyses). Data collection took place one-on-one in a quiet, private location at the tribal college, located a short distance from the SUD treatment center. Refreshments were provided as is the cultural norm for visiting. Informed consent involved a discussion of the history of the project and its rationale, in addition to typical informed consent information about risks and benefits of participating in a study of this nature. We explained that the survey would ask very personal and sensitive questions that might be upsetting, but assured participants that our job was to listen to them, not to judge them. We also took efforts to normalize the struggle that many people have with addiction, explaining our perspective that recovery is a process with relapse being the norm, not the exception, and expressing hope and optimism for future wellness. During the informed consent process, the researchers disclosed some personal information and shared who we were, where we came from, and why we were interested in studying this topic. For example, interviewers disclosed personal or family experiences with addiction and recovery as a way to build rapport. We also took time to ask about the participants' families, interests, and concerns before beginning data collection. 
Following the informed consent process, the researchers administered the Timeline Followback (Sobell \& Sobell, 1992), a calendar-based recall method widely used to assess alcohol and drug consumption over a specific time period, in interview format. We emphasized the importance of providing accurate data to the best of their ability and promised not to disclose information about their substance use to anyone else. With knowledge of literacy challenges among some participants, the interviewers then offered participants the opportunity to complete the rest of the survey packet on their own or to have the remaining questions read to them in interview format. If the participant hesitated when making this decision, they were asked, "How happy are you with your reading?" If they indicated having trouble with reading, the interviewers read the survey items aloud and recorded the participant's responses. About half of the participants required or preferred interview format. The surveys took about two hours to complete, and participants received a $\$ 50$ gift card in compensation. Participants also received a list of referrals to health care and social services resources available in the community and were offered assistance in contacting them. Finally, participants were invited to ask questions or share other information with the research team member. Many participants remained long after the survey was complete to ask questions and talk about their struggles with SUD, and the researchers stayed with them and listened as long as they wanted to keep talking.

In addition to assessing study acceptability to participants through informal conversations after the surveys were completed, we also gathered quantitative data about their experiences completing the survey using the brief Reactions to Research Participation Questionnaire (RRPQ; Newman et al., 1999). This three-item measure includes the following items, rated on a 5-point scale from Strongly Disagree (1) to Strongly Agree (5): "I gained something positive from participating in this study;" "Completing this study upset me more than I expected;" and "Had I 
known what this study would be like, I still would have agreed." In the following section we present demographics and substance use data for our sample as well as results from the RRPQ questions used to assess participants' experiences with the survey.

\section{Descriptive Data}

Participants were 198 AI adults, aged $18-65\left(M_{a g e}=37.39\right.$ years, $M d=36$ years, $S D=$ 11.79), and included women $(n=103,52 \%)$ and men $(n=95,48 \%)$. See Table 1 for a summary of participant characteristics. All participants were residents of one reservation, which has approximately 10,000 residents spread across over two million acres. Of the participants, 71 (35.9\%) had attended boarding school at some point in their lives, whereas $127(64.1 \%)$ had not. Also, 59 participants $(29.8 \%)$ had been placed in foster care as a child and $139(70.2 \%)$ had not. Regarding having been given an Indian name, 57 participants $(28.8 \%)$ responded affirmatively, and $141(71.2 \%)$ had not received an Indian name. With regard to substance use, the primary substances used were alcohol and methamphetamine, with many participants reporting polysubstance use. In the 90 days prior to assessment, participants consumed alcohol on a mean of 19.56 days $(M d=7 ; S D=26.88)$ and, after filtering out six extreme outliers, the mean number of standard drinks per drinking day was $16.30(M d=13.50 ; S D=10.39$; see Table 1$)$. It is important to note that this heavy level of alcohol consumption is not typical of AI people - the present sample consisted of individuals who reported struggling with substance abuse.

With regard to other drug use, participants reported consuming illicit drugs on a mean of 28 days $(M d=6.5, S D=39.86)$ in the 90 -day assessment period. The majority of the sample $(n=$ $107,54 \%$ ) reported having previously received SUD treatment, with $74.1 \%$ of these participants reporting that they had adequate support from relatives when they sought treatment. The primary treatment modalities received were the on-reservation intensive outpatient program $(n=90$, 
45.5\%) and off-reservation inpatient treatment $(n=53,26.8 \%)$. Moreover, 95 participants (48\%) had attended Alcoholics Anonymous meetings and 41 participants $(20.7 \%)$ had attended Narcotics Anonymous meetings at some point in their lives. A minority of the sample had ever seen a counselor or psychologist $(n=61,30.8 \%)$, had received behavioral health services through the Indian Health Service $(n=42,21.2 \%)$, or had participated in a traditional recovery ceremony (recovery sweat lodge; $n=31,15.7 \%)$. Most participants $(69.2 \%)$ reported currently having adequate support from their relatives for their recovery, but $29.8 \%$ did not. These data reflect a need for treatment and recovery support among participants, and suggest that word of mouth is an effective way to recruit a sample of AI people with substance use problems.

\section{Reactions to Research Participation}

Evidence in support of the CBPR process can be found in the success of participant recruitment into this study. After conducting the first few interviews, word spread rapidly throughout the reservation and we had over 200 people requesting to participate in the survey within a month. Gone and Calf Looking (2015) wrote, “... any new undertaking on the reservation usually does not draw wider participation until positive word about the project can spread throughout the community along the "moccasin grapevine"' (p. 86). For every scheduled data collection occasion, there were potential participants lined up at the tribal college to see if they or their friends might enroll in the study. The project manager kept a list of all interested potential participants and we aimed to collect data on a first-come, first-served basis, to the best of our ability. The study took one year to complete not because of difficulty recruiting participants but due to the length of the interviews. The enthusiastic interest from the target population can be considered one metric of the project's success.

Evidence of a positive experience with the survey can be found not only in the participant 
turnout, suggesting a positive reputation among participants traveling quickly throughout the community, but also in our observations during the data collection process and the feedback participants offered. As stated previously, many participants remained to visit with the interviewers after data collection was complete, asking questions about the study and sharing reflections on the survey questions. Several stated that they had never been asked some of the questions included in the survey before and found it helpful to reflect on their experiences. They reported enjoying the process and expressed gratitude for the opportunity to discuss their substance use with someone they trusted to maintain their confidentiality, and expressed that this was a rare occurance on the reservation. The promise of confidentiality in the informed consent document helped reassure participants that their identifiable data would be protected. Furthermore, many asked if they could refer their partner/friend/relative to the study, which we interpreted as evidence of the acceptability of the survey and study methods.

Participants' responses to the three items from the Reactions to Research Participation Questionnaire also provide evidence for the acceptability of the survey and study methods. Findings showed that $71.3 \%$ of the sample agreed or strongly agreed that they gained something positive from participating in the study, $25.1 \%$ answered "neutral," and only $3.6 \%$ disagreed or strongly disagreed. In response to the second question, $79.9 \%$ disagreed or strongly disagreed with the statement that completing the study was more upsetting than expected, $12.9 \%$ answered “neutral," and 7.2\% agreed or strongly agreed. In response to the third question, $67.7 \%$ agreed or strongly agreed that, had they known what the study would be like, they still would have participated, whereas $22.1 \%$ answered "neutral," and 10.3\% disagreed or strongly disagreed. Taken together, it appears that the majority of participants had a good experience with the survey and would be willing to engage in similar research in the future. 


\section{Discussion}

The success of our project in quickly recruiting a large number of reservation-based AI tribal members who self-reported struggling with alcohol or drugs represents an important step forward for AI/AN SUD research, which has been stymied by irresponsible and unethical research in the past, along with stigma and shame resulting from stereotypes held about AIs and addiction. Although there have been a number of substance use research studies conducted with AI/AN participants since the unfortunate events of the Barrow Alcohol Study (e.g., Manson et al., 2005; Spicer et al, 2003; Whitesell et al., 2009, among others), the pace and scope of research has not been commensurate with the health disparities affecting $\mathrm{AI} / \mathrm{AN}$ populations, and pales in comparison to the pace of SUD research conducted with other racial and ethnic groups.

Given the cultural and historical context of alcohol and the well-justified distrust of researchers in Native communities, one useful approach to SUD research with AI/ANs is to focus on strengths and protective factors. An exemplar of this approach can be found in the People Awakening Study, conducted by Mohatt and colleagues to investigate pathways to sobriety among AN people (e.g., Allen et al., 2014; Mohatt, Hazel et al., 2004; Mohatt, Rasmus et al., 2004; Mohatt et al., 2007). However, our partnership also wanted to understand risk factors in addition to protective factors that influence substance use on the reservation in order to design effective, locally acceptable interventions that consider the community and cultural context. The survey we collaboratively developed included a balance of risk and protective factors that were grounded in our qualitative data as well as the extant literature, and was thoroughly vetted by community partners and approved by the tribal IRB. Despite our culturally responsive community engagement methods and close involvement of community partners, we did not know what to expect in terms of recruitment or acceptability of the survey to our target 
population. Through our collaborative efforts, we learned that this reservation community is interested in and ready for research on SUD, if conducted respectfully and through a CBPR partnership that values knowledge co-production above data extraction.

Findings from the Reactions to Research Participation Questionnaire, where $96.4 \%$ of our sample reported gaining something positive from participating in the survey, $92.8 \%$ did not find the survey questions to be more upsetting than they expected, and $89.7 \%$ said they still would have participated in the survey if they had known what it would be like beforehand, further reflect success in community-engaged SUD research. It is not surprising that a small number of participants did find the questions upsetting, as they inquired about very sensitive topics like having experienced childhood abuse and neglect. Occasionally participants disclosed feelings of guilt and shame over neglecting their own children due to their addictions, and others reported painful traumatic experiences such as sexual assault and intimate partner violence. Questions about historical trauma also triggered strong emotions for some participants. We expected that some participants would feel distress during the survey, which is one reason for the full board review by two IRBs and the safety plan we had in place (but did not need to use). However, other participants answered questions comfortably, even asking "What was meant to have upset me?" in response to the question. Most participants reported feeling a sense of relief after disclosing painful experiences with the researchers. Still, a minority of participants $(10.3 \%)$ reported that they would not have participated in the survey if they had known what it would be like. Although we did not assess which characteristics of the survey influenced these responses, the length and tediousness of data collection likely played a role. In the future, we would make efforts to simplify and streamline the survey, or conduct it on two separate occasions.

\section{Ways We Enhanced Participation}


Upon reflection, we have identified strategies that we believe facilitated recruitment and enhanced participation in our study. First, as stated previously, we were committed to an equitable partnership and CBPR principles, which allowed us to build a positive reputation in the community before launching the survey. We developed the survey collaboratively and committed to a process of knowledge co-production that carefully and reciprocally considers the interests, expertise, and knowledge systems being brought to bear on issues related to SUD from an academic and community co-researcher perspective. The survey questions asked about topics the participants knew and cared about — namely, their own substance use, beliefs about addiction, social support networks, cultural identity, coping styles, spiritual beliefs, trauma histories, etc. We aimed to honor and value the participants' knowledge and expertise through the questions we asked, the time we spent together, and the information we shared not only about our research but about ourselves. All participants are experts on their own experiences, and it is only through the sharing of this knowledge that the field continues to develop.

Regarding the survey process, we aimed to use best practices in interviewing techniques, and believe that our careful attention to culturally responsive interviewing enhanced recruitment in this population. Trust with participants was built first through self-disclosure and having informal discussions about who we were, where we came from, and why we were interested in studying addiction; this enabled us to build rapport and demonstrate our personal connection to the topic and to the community. Community members who served as interviewers were able to find distant familial or social connections with nearly every participant they met. Interviewers who were not members of the community often would find connection leading to trust and mutual understanding by sharing the impacts of SUD on their lives and families. We maintained a nonconfrontational, nonjudgmental approach throughout the survey by using reflective 
listening and expressing genuine interest in understanding the issue from the participant's view. Through the interviewers' expression of positive regard and warmth, and continued assurances of confidentiality, most participants became comfortable disclosing sensitive personal information, as evidenced by the high rates of substance use they reported.

Following data collection, we spent additional time with each participant who wished to ask questions or share information that was not covered in the survey instrument. We also provided contact information for local resources for treatment and encouragement to use them, offering to help connect participants with services they may need (although no participant accepted this offer). We offered fair compensation and expressed genuine gratitude for sharing their expertise. Having community co-researchers conduct the survey also was helpful, as it put participants at ease. As our CAB members noted, seeing a Native face, even an unknown person from a different tribe, sends a message that "this research is for us." In the cases where a nonNative person conducted the survey, the interviewer named the community partners on the team as a way of making connections and establishing trust. We also provided regular progress updates to the $\mathrm{CAB}$, which helped ensure that the community remained engaged, demonstrated respect for the community's knowledge and autonomy, and helped maintain transparency throughout the study. Together, these activities appeared to increase trust and establish the credibility of the project, as evidenced by the widespread word-of-mouth recruitment.

\section{Lessons Learned and Future Directions}

Our partnership embarked upon this study without knowing what to expect in terms of community buy-in and recruitment. We engaged in significant groundwork before launching the survey by developing an equitable partnership based on trust and respect, and by collecting qualitative data from a number of key informants from the community. We disseminated our 
findings to the community and continued to engage in relationship-building activities to ensure cultural relevancy and responsiveness to community needs and priorities. Still, the progression from qualitative to quantitative study methods took time and additional trust building that involved several discussions between the academic and community partners to determine the most effective and respectful ways to gather data, as well as the extent to which survey data can be useful and informative. These discussions would often lead to consideration of the usefulness and appropriateness of Western research paradigms to investigate health inequities in Native communities, and the need to value AI knowledge systems in all stages of the research process.

With trust came truth and greater transparency from community advisors, participants, and co-researchers. For example, on different occasions throughout the project, CAB members expressed frustration with requirements of the funding agency and the need to systematically study a phenomenon that "everyone already knows about." They also expressed frustration with research in general, when the need for treatment services is so apparent. However, the local project manager had many years of experience working on health disparities research projects and was effective at communicating the rationale for investigating a problem carefully before rushing forward with an intervention that may or may not be effective. After airing their frustrations, the $\mathrm{CAB}$ demonstrated a deeper understanding of the research process and funding constraints, and ultimately decided to proceed with the study. The academic partners continued to emphasize the goal of using these data to develop a culturally grounded intervention for SUD that will be sustainable and acceptable in the community. Still, the tensions between the need for research and treatment services continue to surface.

When discussing future directions for this research, the community members who served as interviewers noted that potentially useful data emerged from conversations they had with 
participants during the survey. In particular, the project manager noted that significant losses of loved ones seemed to precede relapses and periods of heavy substance use, and that these losses were extraordinarily frequent. Some participants reported the deaths of several family members due to illness, overdose, or other tragic events just within the 90-day assessment period of the Timeline Followback interview. Recovery was seen as unlikely during these times of tragedy and loss, which for some appeared neverending. The project manager requested that our future work include assessments of grief and loss as risk factors for relapse and barriers to recovery, and the CAB expressed support for this idea. Our team has embraced this line of inquiry and we are preparing a study to examine the association between grief and relapse among AIs with SUD. Additional next steps for this program of research will involve using the findings from this survey along with our previous qualitative findings to develop and implement a culturally grounded, community-based intervention to facilitate recovery from SUD on the reservation. The efficacy of the resulting intervention will be tested, pending future funding and community support. The long-term goal of this program of research is to reduce health disparities and improve quality of life for tribal members. Our long-term CBPR process demonstrates how our team has moved from engaging an AI community in SUD research, to co-producing knowledge about SUD risk and protection, to seeing the community drive research questions and next steps.

\section{Conclusion}

Through the process of conducting the Substance Abuse and Resilience Survey, we learned that it is possible to collect quality quantitative data about sensitive and stigmatized topics from community samples of underserved and underrepresented populations like AIs residing on reservations. We also learned that it is acceptable to inquire about problems and risks, as long as these questions are balanced with others about strengths and protection. The 
speed with which word spread throughout the community served as evidence that the study was well-received by the target population. Further evidence was provided by the enthusiasm of the participants who stayed after the survey was complete to talk further, and by gratitude they expressed for the opportunity to share their experiences. Finally, the RRPQ data also support our assertion that the survey experience was a positive one for most participants.

We contend that studies like this one are crucial for advancing research on health disparities affecting ethnic minority populations in general and AI/AN communities in particular. Researchers who aim to work in partnership with communities should not be dissuaded from addressing risk factors along with protective factors, but should work closely and carefully with their community partners to ensure they do so in a sensitive and respectful way. Through equitable partnership, trust, and transparency, researchers and communities may engage in studies that have the potential to advance health disparities research and improve health equity.

Commitment to CBPR and knowledge co-production is necessary for building the trust that will make successful research possible, particularly when the topic is sensitive and mired in historical injustices. Transparency is crucial—individuals who truly understand what a study aims to do and why it is being conducted are perfectly capable of deciding for themselves whether or not to participate. It is important for researchers to be as honest and forthcoming as possible about the goals of the research, the reason for the questions asked, the anticipated and desired outcomes of the study, and how the data are intended to be used. With full transparency, participants will be able to make truly informed decisions, which will influence how well the study is received. Research is an important component of coordinated efforts to improve health equity in under-served communities, and careful, respectful research methods are crucial for producing actionable knowledge with the potential to solve problems that matter to communities. 


\section{References}

Adamson, S. J., Sellman, J. D., \& Frampton, C. M. (2009). Patient predictors of alcohol treatment outcome: A systematic review. Journal of Substance Abuse Treatment, 36(1), $75-86$.

Allen, J., Mohatt, G. V., Beehler, S., \& Rowe, H. (2014). People Awakening: Collaborative research with Alaska Native rural communities to address alcohol use disorders and suicide health disparities. American Journal of Community Psychology, 54, 100-111.

Allen, J., Rasmus, S., Fok, C. C. T., Trimble, J., Lee, K., \& Qungasvik Team (2019). Reasons for life: A strengths based measure of protection from suicide. Assessment. Advance online publication.

Beauvais, F. (1989). Limited notions of culure ensures research failure. American Indian and Alaska Native Mental Health Research, 2(3), 25-28.

Campbell, A. N., Turrigiano, E., Moore, M., Miele, G. M., Rieckmann, T., Hu, M. C., Kropp, F., Ringor-Carty, R., \& Nunes, E. V. (2015). Acceptability of a web-based community reinforcement approach for substance use disorders with treatment-seeking American Indians/Alaska Natives. Community Mental Health Journal, 51(4), 393-403.

Centers for Disease Control and Prevention (2018). National Center for Health Statistics: National Health Interview Survey, 2017. Retrieved 9-20-19 from: https://www.cdc.gov/nchs/nhis/shs/tables.htm

Compton, W. M., Thomas, Y. F., Stinson, F. S., \& Grant, B. F. (2007). Prevalence, correlates, disability, and comorbidity of DSM-IV drug abuse and dependence in the United States: Results from the National Epidemiologic Survey on Alcohol and Related Conditions. Archives of General Psychiatry, 64(5), 566-576. 
Cunningham, J. K., Solomon, T. A., \& Muramoto, M. L. (2016). Alcohol use among Native Americans compared to Whites: Examining the veracity of the 'Native American elevated alcohol consumption' belief. Drug and Alcohol Dependence, 160, 65-75.

Dillard, D. A., Caindec, K., Dirks, L. G., \& Hiratsuka, V. Y. (2018). Challenges in engaging and disseminating health research results among Alaska Native and American Indian people in Southcentral Alaska. American Indian and Alaska Native Mental Health Research, 25, 3-18.

Duran, B., Oetzel, J., Lucero, J., Jiang, Y., Novins, D. K., Manson, S., \& Beals, J. (2005). Obstacles for rural American Indians seeking alcohol, drug, or mental health treatment. Journal of Consulting and Clinical Psychology, 73(5), 819.

Foulks, E. F. (1989). Misalliances in the Barrow Alcohol Study. American Indian and Alaska Native Mental Health Research, 2(3), 7-17.

Gone, J. P., \& Calf Looking P. E., (2015). The Blackfeet Indian culture camp: Auditioning an alternative indigenous treatment for substance use disorders. Psychological Services, 12(2), 83-91.

Grant, B. F., Goldstein, R. B., Saha, T. D., Chou, S. P., Jung, J., Zhang, H., Pickering, R. P., Ruan, W. J., Smith, S. M., Huang, B., \& Hasin, D. S. (2015). Epidemiology of DSM-5 alcohol use disorder: Results from the National Epidemiologic Survey on Alcohol and Related Conditions III. JAMA Psychiatry, 72, 757-766.

Grant, B. F., Saha, T. D., Ruan, W. J., Goldstein, R. B., Chou, S. P., Jung, J., Zhang, H., Smith, S. M., Pickering, R. P., Huang, B., \& Hasin, D. S. (2016). Epidemiology of DSM-5 drug use disorder: Results from the National Epidemiologic Survey on Alcohol and Related Conditions-III. JAMA Psychiatry, 73, 39-47. 
Greenfield, B. L., \& Venner, K. L. (2012). Review of substance use disorder treatment research in Indian country: Future directions to strive toward health equity. The American Journal of Drug and Alcohol Abuse, 38(5), 483-492.

Hartz, D. T., Frederick-Osborne, S. L., \& Galloway, G. P. (2001). Craving predicts use during treatment for methamphetamine dependence: A prospective, repeated-measures, withinsubject analysis. Drug and Alcohol Dependence, 63(3), 269-276.

James, C. V., Moonesinghe, R., Wilson-Frederick, S. M., Hall, J., Penman-Aguilar, A., \& Bouye, K. (2017). Racial/ethnic health disparities among rural adults_-United States, 2012-2015. MMWR Surveillance Summaries 66, no. 23: 1-9.

Johnson, L. E., \& Benight, C. C. (2003). Effects of trauma-focused research on recent domestic violence survivors. Journal of Traumatic Stress, 16, 567-571.

Indian Health Service, U.S. Department of Health and Human Services (2018). Indian Health Disparities. Retrieved 10-23-19 from: https://www.ihs.gov/newsroom/factsheets/disparities/

Mail, P. D. (2002). Multiple perspectives on alcohol and the American Indian. Alcohol Use Among American Indians: Multiple Perspectives on a Complex Problem (NIAAA Research Monograph No. 37), 3-23.

Manson, S. M. (2000). Mental health services for American Indians and Alaska Natives: Need, use, and barriers to effective care. The Canadian Journal of Psychiatry, 45, 617-626.

Manson, S. M., Beals, J., Klein, S. A., Croy, C. D., \& AI-SUPERPFP Team. (2005). Social epidemiology of trauma among two American Indian reservation populations. American Journal of Public Health, 95, 851-859.

May, P. A., McCloskey, J., \& Gossage, J. P. (2002). Fetal alcohol syndrome among American 
Indians: Epidemiology, issues, and research review. Alcohol Use Among American Indians and Alaska Natives: Multiple Perspectives on a Complex Problem, 321-369.

Mohatt, G. V., Hazel, K. L., Allen, J., Stachelrodt, M., Hensel, C., \& Fath, R. (2004). Unheard Alaska: Culturally anchored participatory action research with Alaska Natives. American Journal of Community Psychology, 33, 263-273.

Mohatt, G. V., Rasmus, S. M., Thomas, L., Allen, J., Hazel, K., \& Hensel, C. (2004). “Tied together like a woven hat:" Protective pathways to Alaska native sobriety. Harm Reduction Journal, 1, 1-12.

Mohatt, G. V., Rasmus, S. M., Thomas, L., Allen, J., Hazel, K., \& Marlatt, G. A. (2007). Risk, resilience, and natural recovery: A model of recovery from alcohol abuse for Alaska Natives. Addiction, 103, 205-215.

Newman, E., Walker, E. A., \& Gefland, A. (1999). Assessing the ethical costs and benefits of trauma-focused research. General Hospital Psychiatry, 21, 187-196.

Novins, D. K., Beals, J., Moore, L. A., Spicer, P., Manson, S. M., \& AI-SUPERPFP Team. (2004). Use of biomedical services and traditional healing options among American Indians: Sociodemographic correlates, spirituality, and ethnic identity. Medical Care, 42, 670-679.

Pruss-Ustun, A., Wolf, J., Corvalan, C., Neville, T., Bos, R., \& Neira, M. (2017). Diseases due to unhealthy environments: An updated estimate of the global burden of disease attributable to environmental determinants of health. Journal of Public Health, 39, 464-475.

Rasmus, S., Charles, B., John, S., \& Allen, J. (2019). With a spirit that understands: Reflections on a long-term community science initiative to end suicide in Alaska. American Journal of Community Psychology, 64, 34-45. 
Rieckmann, T., McCarty, D., Kovas, A., Spicer, P., Bray, J., Gilbert, S., \& Mercer, J. (2012). American Indians with substance use disorders: Treatment needs and comorbid conditions. The American Journal of Drug and Alcohol Abuse, 38, 498-504.

Saremi, A., Hanson, R. L., Tulloch-Reid, M., Williams, D. E., \& Knowler, W. C. (2004). Alcohol consumption predicts hypertension but not diabetes. Journal of Studies on Alcohol, 65, 184-190.

Skewes, M. C., \& Blume, A. W. (2019). Understanding the link between racial trauma and substance use among American Indians. American Psychologist, 74, 88-100.

Skewes, M. C., Hallum-Montes, R., Gardner, S. A., Blume, A. W., Ricker, A., \& FireMoon, P. (2019). Partnering with Native communities to develop a culturally grounded intervention for substance use disorder. American Journal of Community Psychology, 64, $72-82$.

Sobell, L., \& Sobell, M. (1992). Timeline Followback: A technique for sssessing self reported alcohol consumption. In J. Allen (Ed.), Measuring alcohol consumption: Psychosocial and biological methods, (pp. 41-72). Totowa, NJ: Humana Press.

Spicer, P., Beals, J., Croy, C. D., Mitchell, C. M., Novins, D. K., Moore, L., Manson, S. M., \& AI-SUPERPFP Team. (2003). The prevalence of DSM-III-R alcohol dependence in two American Indian populations. Alcoholism: Clinical and Experimental Research, 27, $1785-1797$.

Tann, S. S., Yabiku, S. T., Okamoto, S. K., \& Yanow, J. (2007). TRIADD: The risk for alcohol abuse, depression, and diabetes multimorbidity in the American Indian and Alaska Native population. American Indian and Alaska Native Mental Health Research, 14, 1-23.

Venner, K. L., Greenfield, B. L., Hagler, K. J., Simmons, J., Lupee, D., Homer, E., Yamutewa, 
Y., \& Smith, J. E. (2016). Pilot outcome results of culturally adapted evidence-based substance use disorder treatment with a Southwest Tribe. Addictive Behaviors Reports, 3, 21-27.

Wallerstein, N. B., \& Duran, B. (2006). Using community-based participatory research to address health disparities. Health Promotion Practice, 7, 312-323.

Wallerstein, N., \& Duran, B. (2010). Community-based participatory research contributions to intervention research: The intersection of science and practice to improve health equity. American Journal of Public Health, 100(S1), S40-S46.

Wexler, L., Chandler, M., Gone, J., Cwik, M., Kirmayer, L. J., LaFronboise, T., Brockie, T., O’Keefe, V., Walkup, J., \& Allen, J. (2015). Advancing suicide prevention research with rural American Indian and Alaska Native populations. American Journal of Public Health, 105, 891-899.

Wexler, L., Hill, R., Bertone-Johnson, E., \& Fenaughty, A. (2008). Correlates of Alaska Native fatal and nonfatal suicidal behaviors 1990-2001. Suicide and Life-Threatening Behavior, 38, 311-320.

Whitbeck, L. B., Chen, X., Hoyt, D. R., \& Adams, G. W. (2004). Discrimination, historical loss and enculturation: Culturally specific risk and resiliency factors for alcohol abuse among American Indians. Journal of Studies on Alcohol, 65, 409-418.

Whitbeck, L. B., Adams, G. W., Hoyt, D. R., \& Chen, X. (2004). Conceptualizing and measuring historical trauma among American Indian people. American Journal of Community Psychology, 33, 119-130.

Whitesell, N. R., Beals, J., Crow, C. B., Mitchell, C. M., \& Novins, D. K. (2012). Epidemiology and etiology of substance use among American Indians and Alaska Natives: Risk, 
protection, and implications for prevention. The American Journal of Drug and Alcohol Abuse, 38, 376-382.

Whitesell, N. R., Beals, J., Mitchell, C. M., Manson, S. M., Turner, R. J., \& AI-SUPERPFP Team. (2009). Childhood exposure to adversity and risk of substance-use disorder in two American Indian populations: The meditational role of early substance-use initiation. Journal of Studies on Alcohol and Drugs, 70(6), 971-981.

Wiechelt, S. A., Gryczynski, J., Johnson, J. L., \& Caldwell, D. (2012). Historical trauma among urban American Indians: Impact on substance abuse and family cohesion. Journal of Loss and Trauma, 17(4), 319-336.

Wu, L., Zhu, H., \& Ghitza, U. E. (2018). Multicomorbidity of chronic diseases and substance use disorders and their association with hospitalization: Results from electronic health records data. Drug and Alcohol Dependence, 192, 316-323.

Yuan, N. P., Eaves, E. R., Koss, M. P., Polacca, M., Bletzer, K., \& Goldman, D. (2010).

"Alcohol is something that been with us like a common cold:" Community perceptions of American Indian drinking. Substance Use \& Misuse, 45, 1909-1929.

Zuckerman, S., Haley, J., Roubideaux, Y., \& Lillie-Blanton, M. (2004). Health service access, use, and insurance coverage among American Indians/Alaska Natives and Whites: What role does the Indian Health Service play? American Journal of Public Health, 94, 53-59. 
Table 1. Participant Characteristics $(N=198)$

\begin{tabular}{|c|c|}
\hline Characteristics & Values \\
\hline Women, $n(\%)$ & $103(52)$ \\
\hline \multirow[t]{2}{*}{ Age in years, mean $(S D)$, range } & $37(11.79)$ \\
\hline & $18-65$ \\
\hline Received an Indian name, $n(\%)$ & $57(29.9)$ \\
\hline Attended boarding school, $n(\%)$ & $71(35.9)$ \\
\hline Placed in foster care, $n(\%)$ & $59(29.8)$ \\
\hline Had adequate social support for recovery, $n(\%)$ & $147(74.1)$ \\
\hline \multicolumn{2}{|l|}{ Education, $n(\%)$} \\
\hline Some high school & $99(50.2)$ \\
\hline High school graduate/GED & $67(34)$ \\
\hline Some college/college degree & $25(12.7)$ \\
\hline \multicolumn{2}{|l|}{ Monthly Income, $n(\%)$} \\
\hline No Income Reported & $50(25.3)$ \\
\hline$\$ 0$ & $67(34.3)$ \\
\hline$\$ 1-\$ 500$ & $26(13.1)$ \\
\hline$\$ 500-\$ 1,000$ & $30(14.6)$ \\
\hline$\$ 1,000-\$ 2,000$ & $10(5.1)$ \\
\hline$>\$ 2,000$ & $15(7.5)$ \\
\hline \multicolumn{2}{|l|}{ Alcohol Use Days in the Past 90 Days, $n(\%)$} \\
\hline $90-60$ days & $24(12.1)$ \\
\hline 59-30 days & $22(11.1)$ \\
\hline 1-29 days & $96(48.5)$ \\
\hline 0 days & $50(25.3)$ \\
\hline \multicolumn{2}{|l|}{ Drug Use Days in the Past 90 Days, $n(\%)$} \\
\hline 90-60 days & $51(25.8)$ \\
\hline $60-30$ days & $13(6.6)$ \\
\hline 1-30 days & $52(26.3)$ \\
\hline 0 days & $76(38.4)$ \\
\hline \multicolumn{2}{|l|}{ Drinks Per Drinking Day, $n(\%)$} \\
\hline 0 (non-drinker, drug use only) & $56(28.3)$ \\
\hline $1-10$ drinks & $48(24.2)$ \\
\hline 11-20 drinks & $49(24.8)$ \\
\hline 21-30 drinks & $27(13.6)$ \\
\hline $31+$ drinks & $18(9.1)$ \\
\hline \multicolumn{2}{|c|}{ Previous Substance Use Disorder Treatment, $n(\%)$} \\
\hline None & $55(27.8)$ \\
\hline Outpatient (on-reservation) & $90(45.5)$ \\
\hline Inpatient (off-reservation) & $53(26.8)$ \\
\hline
\end{tabular}

